\title{
People and their walking environments: An exploratory study of meanings, place and times
}

\author{
Eric T.H. Chan * 123 \\ Tingting Elle Li 4 \\ Tim Schwanen 1 \\ David Banister 1
}

1 Transport Studies Unit, School of Geography and the Environment, University of Oxford, South Parks Road, Oxford, OX1 3QY, UK

2 School of Engineering, Newcastle University, Newcastle upon Tyne, NE1 7RU, UK

3 The Alan Turing Institute, British Library, 96 Euston Road, London NW1 2DB, UK

${ }^{4}$ London Geller College of Hospitality and Tourism, University of West London, St Mary's Road, Ealing, London, W5 5RF, UK

* corresponding author:

ericthchan@gmail.com

Paper prepared for submission to:

International Journal of Sustainable Transportation 


\title{
People and their walking environments: An exploratory study of meanings, place and times
}

\begin{abstract}
Seen as the most sustainable transport mode, people's walking behaviour has been well investigated in relation to its environmental correlates and benefits to physical and mental well-being in current transportation and public health literature. Much of this research has considered that environmental features determine people's responses, behaviours and level of satisfaction above individual or collective subjectivities. Nonetheless, more scholars begin to argue that people's responses to environments could be highly complex, depending on personal background, past experiences and emotional interpretation of the place. The meanings that people attach to their walking practices may differ by personal, social and cultural contexts, which consequently influence how they perceive and experience their walking environments. The transferability of the westernised understandings of walking to other developing cities, thus, is questionable, and will need to be examined empirically. This study focuses on a rapidly developing Chinese city, and explores how pedestrians in Shenzhen respond to the walking environment through their articulation of walking practices. Through analysing life stories of twenty local residents, three interrelated themes emerged to highlight the significance of meanings attached to walking, engagements with timescapes and attachment to place, illustrating how these themes were entangled with walking experiences. Insights from this study will enable future studies to reconceptualise the relationship between pedestrians and their environments as a more dynamic process which should take into consideration the temporalities of the walking environment and pedestrians' bodily and emotional capacities.
\end{abstract}

Keywords: walking experience, built environment, meaning, temporality, place attachment, urban China 


\section{Introduction}

An established body of research has examined people's walking behaviour, its environmental correlates and benefits to physical and mental health by developing quantifiable indicators and scales to measure walking behaviour, walkability and well-being (Andrews, Hall, Evans, \& Colls, 2012; Dovey \& Pafka, 2019; Kelly, Murphy, \& Mutrie, 2017; Vale, Saraiva, \& Pereira, 2016). Much of this literature has heavily emphasised the environmental factors that stimulate walking, which was based on the assumption that environmental features determine people's responses, behaviour and satisfaction above individual or collective subjectivities (Andrews et al., 2012). However, this assumption has been challenged by researchers arguing that people's responses to their environments may not be consistent but highly complex depending on personal background, past experiences and emotional interpretation of the place (Ambrey \& Bitzios, 2018; Kwan, 2018; Mennis \& Mason, 2011). These factors can significantly mediate pedestrians' responses to the built environment and shape their walking behaviour (Kwan, 2018). Given that the existing understanding about pedestrians' perceptions and interpretations of their environments are still relatively limited, these factors are not commonly captured by traditional methods nor taken into consideration in existing walking studies. Therefore, it is timely to involve more qualitative information to explore pedestrians' knowledge, perceptions, interpretations, and the unique meanings ascribed to their daily walking experience.

Moreover, much research on walking and walkability has been based on empirical data from western geographical contexts and even, if the focus is on non-western settings, the grounding is based in Euro-American theories and worldviews. Overlooking the complexities of contextual influences and lacking sensitivities of cultural specificity may have ramifications, given that the meanings and experiences associated with walking are deeply embedded in unique cultural traditions (Bruner, 1990), and may not be universal in nature, but contingent upon specific historical and geographical contexts. Thus, findings based on western settings may not be transferrable to other socio-cultural contexts. More new research from the non-western context is urgently needed to 
move beyond the use of existing theories, approaches, value systems and worldviews in order to open up new dialogues that allow non-western experiences, ideas and concepts to be articulated (Schwanen, 2018).

In light of these considerations, the present study focuses on a rapidly developing city in Southern China, and explores how urban pedestrians in Shenzhen articulate the meanings and experiences of their daily walking practices. Shenzhen is one of the earliest cities to implement detailed planning for the development of pedestrian system in China. With its unique history as a special economic zone and urban features with high population density, it has become a world-renowned metropolis which has witnessed rapid economic and urban development. Situated in this urban context, this research adopts a qualitative design using in-depth interviews to explore the lived experiences of Shenzhen pedestrians and attend to contextual specificities of walking behaviour as a part of relational and complex interactions with time, bodies and places (Atkinson, 2013). Based on inductive analysis of 20 in-depth interviews with Shenzhen residents who were residing in their neighbourhoods and conducted walking trips at least 2 times per week. This study provides a more contextualised comprehension of how pedestrians interpret, respond to, and perceive their walking environments in a rapidly developing city context.

\section{Literature review}

The literature on walking and walkability extensively spans across multiple disciplines. Here, we focus on two strands of literature highlighting the complexity of the practice of walking and the multifaceted interactions of the pedestrians and the walking environment. The first sub-section focuses on the practice and experience of walking, which emphasises walking as a diverse activity, while the second sub-section highlights the tangible (physical) and intangible (social, cultural and emotional) interactions between the pedestrians and the environment.

\subsection{Walking as embodied social practice}


A rich and multi-disciplinary body of scholarship has portrayed walking as an embodied social practice and multi-sensuous experience. Various types of walking practices have been examined, including on mountains trails (Lorimer \& Lund, 2008), urban explorations (Pinder, 2005), and reflections upon landscapes (Wylie, 2009). Work in this vein has offered insightful understandings of walking as not only a destination-oriented mode of transport but also a form of fluid and active movement that involves body, mind and space and varies in terms of purpose, pace, gait, and rhythm (Lorimer, 2011; Wunderlich, 2008). For example, Edensor (2010) applied Lefebvre's (2004) rhythmanalysis to explore walking and emphasised walking as experiential flow of moments that consists of sensory and affective engagement of physical and mental states and illustrated how place (and sense of place) is produced through walking. Waitt, Stratford, \& Harada (2019) incorporated the assemblage thinking (Deleuze \& Guattari, 1988) and the concept of territory to examine walking in Wollongong by considering pedestrians as "an ongoing relational achievement of entities both social and material" (p.927). In sum, these studies and the associated conceptual frameworks provided useful insights to understand walking experience as complex entanglements of pedestrians, the environment and the practices of walking.

By providing narratives through "walking-thinking-writing", these studies have provided thought-provoking perspectives with in-depth understandings of how pedestrians engage in purposeful, reflective and nurturing walking practices (Horton et al., 2014; Ingold \& Vergunst, 2008). Key characteristics of these walking practices are highlighted, including their complexly sensed nature; the bodily, emotional, and sociotechnical attentiveness that is involved; and the connections that are invoked between landscapes, emotions and memories (Pinder, 2005).

Nonetheless, walking is rarely seen as just walking in these new walking studies, but often as extraordinary, revelatory and sometimes sacred and spiritual. Some studies have, therefore, sought to understand everyday walking by focusing on the "less remarkable, unspectacular and unreported everyday experiences 
associated with walking" (Middleton, 2010, p. 576), and exploring habitual and less "willful and artful" walking practices (Horton et al., 2014, p. 98). Studying walking practices in London, Middleton (2009; 2010; 2018) has observed that most journeys in everyday walking practices are not the outcome of rational intention or decision-making. She argues that more attention should be given to the processual and experiential dimensions of walking itself (Middleton, 2011). Everyday urban walking involves all kinds of verbal and non-verbal interactions among pedestrians and other road users; "walking together" can create and extend supportive social spaces that strengthen community cohesion and social interaction (Middleton, 2018; see also Doughty, 2013).

The above studies have highlighted the differentiated nature of walking, with various purposes and respective practices. These walking studies have provided rich insights that advanced our understanding of walking (Pooley et al., 2014; Shortell \& Brown, 2014; Middleton, 2010). Nonetheless, the foci of most of these walking studies have been based on case studies from the developed western (global North) cities; similar work that explores walking in developing city contexts and outside the global North is very sparse. One exception is a study of the walking experiences of young people in Riyadh, Saudi Arabia. In this study, Almahmood et al. (2017) have shown that the practice of walking in an Islamic city is heavily shaped by gender norms and traditions. Women in Riyadh tend to walk in "privatised" spaces like shopping malls, because these spaces can "justify" their presence (to go out for shopping is a socially acceptable reason to for women to walk), and young women are prevented to walk in urban spaces to avoid any unpleasant gendered encounters. This study suggests that the meanings, practice, and experience of walking in developing cities in the global South may be significantly different from our current understandings, which will deserve further investigations.

\subsection{Contextual uncertainty of environmental influences on walking}

The term "context" has been used to describe the circumstantial environment for certain activities to take place, such as social, physical, cultural environments that shape an individual's behaviour and experience (Orton et al., 2017; Taylor, 
Clark, \& Gilliland, 2018; Bean, Kearns, \& Collins, 2008). In studies of walking and environment, one of the basic assumptions is that the environmental influences to behaviour are reasonably consistent among all individuals and they respond in more or less similar ways. However, given that places (and environments) are social constructions named, bounded and experienced differently by different individuals (Lee, Oropesa, \& Kanan, 1994), people's responses to their environments could be highly personal and vary significantly by their background, past experience, perceptions, emotions and interpretations to the environment (Kwan, 2018; Coulton, Jennings, \& Chan, 2013; Mennis \& Mason, 2011). As a result, the contextual influences on individual's behaviour and experience will be highly complex and idiosyncratic, as the same environmental factors may lead to different behavioural outcomes due to various personspecific attributes (Kwan, 2018).

Although contextual influences play a critical role in shaping individuals' health, energy-consumption and travel behaviour (Aldred \& Jungnickel, 2014; Fitt, 2017; Stephenson et al., 2015; Viner et al., 2012), the extant studies on people's walking experiences and behaviour in the public health and transportation literature have largely focused on the role of physical infrastructure. Relatively few studies have addressed the question of how the effects of social and cultural contexts affect people's walking, even though these contextual factors may significantly mediate individuals' perceptions and their associated walking experience and behaviour. For instance, some studies have explored how and in what ways social and cultural meanings ascribed to walking shape individual's daily walking. Using a qualitative method, Fitt (2017) examined how social meanings associated with individual's status, accomplishment, risk, and body shape in modifying their walking behaviour and other commute mode choice decisions in New Zealand. Focusing on low-income urban mothers in the United States, Segar et al. (2017) found that walking was associated with negative meanings, such as low socio-economic status, psycho-social stress, and little control over physical environments, which affected urban mothers' priorities to walk. These studies have highlighted the complexity of social and cultural factors and their influences on people's walking behaviour and experience. 
Apart from social and cultural factors, previous studies have also found that some aspects of pedestrian's characteristics or attributes are significantly associated with walking, such as habit, place attachment and ageing. For instance, habit has been found to be associated with walking behaviour even after residential relocation (Curl, Kearns, Macdonald, Mason, \& Ellaway, 2018) and have positive effects on the affective experience of walking (Johansson et al., 2016). In addition, previous literature has also touched to some extent on the potential relationships between place attachment and people's walking behaviour. For example, Ferreira et al. (2016) showed that the effects of environmental quality on walking intentions and behaviours were mediated by neighbourhood attachment. The literature on ageing can also advance our understanding of walking, by considering how the changes in body functions of older pedestrians shape their preferences towards the walking environment (de Melo, Menec, Porter, \& Ready, 2010) and risks of fall during walking (Curl, Thompson, Aspinall, \& Ormerod, 2016). The aforementioned studies have suggested that the factors associated with pedestrians' habit, place attachment and ageing are associated with their walking experience and behaviour, but more in-depth investigations are needed to understand how these factors shape people's walking experience, particularly outside the context of global North.

\section{Research context and methodology}

\subsection{Research setting}

Located in the Guangdong Province of south China, the city of Shenzhen has a linear shape, stretching about $90 \mathrm{~km}$ from east to west, and $40 \mathrm{~km}$ from north to south. With only $2,050 \mathrm{~km}^{2}$ of land area, the size of Shenzhen is small compared to other major Chinese cities. For example, the land areas of Shanghai and Beijing are three and eight times larger than that of Shenzhen respectively. Despite the relatively small land area, the population is greater than 12.9 million, making Shenzhen one of most densely populated cities in China $\left(6,234\right.$ people $\left./ \mathrm{km}^{2}\right)$.

Shenzhen has witnessed rapid and profound changes in its urban structure during transformation from a fishing village to one of the largest cities in China 
after the Open Door Policy in the late 1970s. However, different parts of the city have experienced dissimilar rates of development and thus created neighbourhoods with distinctive characteristics in terms of development density, land use mix and urban structure. As a result, residents in different parts of the city are likely to have differing walking experiences. To capture the variation of their experiences, we recruited participants from four neighbourhoods with different geographical locations within the city (inner urban and outer urban) and levels of local accessibility ${ }^{1}$ (high and low): Xinzhou (Inner-high), Xinsha (Inner-low), Shangjing (outer-high), Huilongpu (outer-low). The rationale behind and processes of selecting these four neighbourhoods have been discussed in a companion study (Chan, Schwanen, \& Banister, 2019).

\subsection{Fieldwork and data collection}

This study applied a highly exploratory qualitative approach to understand Chinese urban pedestrians' walking experiences. To recruit participants, the first author conducted fieldwork in the selected neighbourhoods between November 2015 and February 2016. First, purposive sampling was adopted to approach residents living in the selected neighbourhood in public spaces who have conducted walking trips at least two times per week. Then, snowball sampling was employed to ask the participants to introduce other potential participants for participation. One of the major challenges for participant recruitment in Shenzhen was the lack of trust while recruiting participants in public spaces, thus, purposive sampling was used to establish an initial contact with local residents, and snowball sampling allowed us to reach participants with diversified socio-demographic characteristics from the referral networks of the present participants. The combination of these sampling techniques was the most effective way to reach the targeted participants in a pre-selected spatial area.

\footnotetext{
${ }^{1}$ Due to the lack of publicly available data on micro-scale built environment features in the case study city, local accessibility was measured by a composite index measuring the distance to the nearest Shenzhen metro station, distance to the nearest park/plaza, and the number of restaurants within the neighbourhood (These variables were chosen as proxy to capture the accessibility to different destinations that are most common for people's daily activities).
} 
A combination of walk-along and sedentary interviews were used for this study because these two methods have their own strengths and weaknesses, which can help to uncover different aspects of people's walking experience. In order to enable participants to articulate their walking experience in the most comfortable way, participants were encouraged to choose either walk-along or sedentary interviews in their preferred locations (including public spaces like parks and cafes or their home) or along preferred routes (footpaths and routes that the participant selected to "walk-along"). In total, three walk-along and seventeen sedentary interviews were conducted. For instance, walk-along interviews can provide rich information on participants' memories, the meanings they associate with walking and the events and thoughts that happened during actual walking situations (Büscher \& Urry, 2009; Carpiano, 2009); while sedentary interviews allow participants to recall the most memorable events and stories that they have encountered in their past walking experience without being focused on or constrained to specific locations.

The final sample includes twenty individuals, of these 12 were female and 8 male, 8 lived in Xinzhou and 5 in Xinsha, 4 in Shangjing and 3 in Huilongpu. Our main purpose is to obtain a wide range of variation in urban walking experience. Thus, instead of drawing a statistically representative sample, we tended to reach individuals in the selected neighbourhoods and collected valuable interpretations from each individual. A set of semi-structured questions was used to guide the sedentary and walk-along interviews, which focused on three aspects: neighbourhood characteristics, walking experience, and the built environment. These questions were carefully prepared, tested and modified through a pilot study with two residents in Shenzhen. Most of the interviews lasted about 60-90 minutes and were audio-recorded. Data saturation was assessed through the counting of occurrences of themes and evaluating the meaning and importance of those themes (Kerr et al., 2010; Hennink et al., 2017). Data saturation was achieved when hardly any new themes relevant to our topic emerged from the new interviews (Guest, Bunce, \& Johnson, 2006). Pseudonyms are used in transcripts to ensure participants' anonymity. 
Interviewees' narratives were considered to be social performances in which realities are crafted in the interactions between interviewer and interviewees (Silverman, 2015). Nonetheless, one of the major concerns when conducting interviews is the power imbalance between researchers and participants. A number of measures have been used in the data collection process to reduce such power imbalance as much as possible, including using open-ended questions to allow participants to talk freely on topics that they are interested in, asking follow-up questions based on participants' responses, and creating a comfortable interview environment according to participants' preferences (Elmir, Schmied, Jackson, \& Wilkes, 2011).

\subsection{Data analysis}

During the first stage of analysis, transcripts were read a number of times to achieve data familiarisation and then coded using NVivo 10. The use of NVivo allows the researchers to organise and manage the transcripts and other data to facilitate the coding process. Initial codes were generated and labeled with the expressions by the participants (Strauss \& Corbin, 1998). These codes were gradually converted into six broader categories: habit, social exchanges, traffic safety, hopes for future, affective responses to urban dynamics, and walk as regimen, all of which participants have identified as significant in interpreting their urban walking experiences. In the second stage, the identified codes and categories were revisited, linked to each case, and developed further. Three more general themes - meaning, timescapes, and place - emerged as the process of abstraction proceeded (Ritchie, Lewis, Nicholls, \& Ormston, 2013). As part of this stage, interactive and iterative discussions and exchanges were conducted between the research team to ensure the consistency and reliability of the themes (Boyatzis, 1998). Coding discrepancies were resolved through full discussions among the authors while unnecessary codes/themes were reduced until final themes, sub-themes and their interrelationships were agreed upon.

\subsection{Limitations}

Limitations in the research design should be acknowledged. First, in terms of sampling, the participant recruitment process may have reduced the inclusion of 
individuals who are less physically active or lack time to visit public spaces, and thus insufficiently explored these individuals' views and experiences. Second, only four neighbourhoods within Shenzhen were selected for analysis, and these cannot represent all conditions and contexts for walking across Shenzhen. The neighbourhoods were selected to make systematic comparisons in terms of distance from the urban core of Shenzhen and local accessibility as part of a broader research project (see Chan et al., 2019). However, future research may involve more neighbourhoods across different districts of Shenzhen.

\section{$4 \quad$ Findings and discussion}

This section discusses three themes that emerged from the two-stage analysis of participants' narratives - meanings, timescapes and place - and how these relate to their walking experiences. In combination, the themes (see also Figure 1) help to deepen our understanding of the contextual complexities (Kwan, 2018; Kwan \& Schwanen, 2018) of urban walking experience.

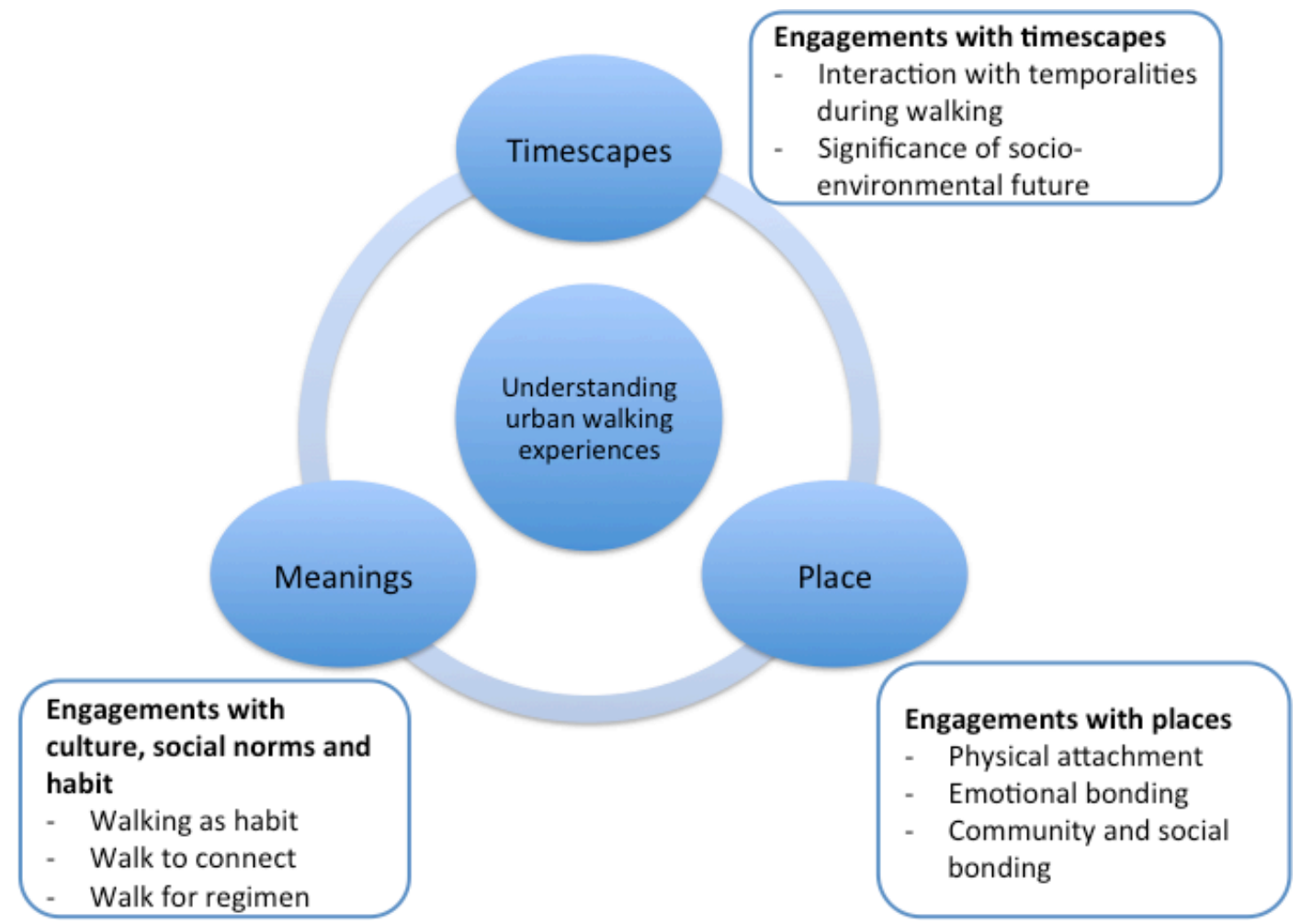

Figure 1. Three major themes in understanding walking experiences in urban China 


\subsection{Meanings of walking in modern China: A habitual practice for harmony and regimen}

\subsubsection{Walking as habitual and self-perpetuating process}

All participants conducted short-distance, routinised trips to access other modes of transport or to access various types of activities at destinations on a daily basis. However, many rarely regarded these trips as walking trips, even though they performed walking every day and regarded it as a habit. This was evident from, among others, the ways in which many participants struggled to describe what these trips meant to them. They only indicated that walking was an automatic and habitual everyday behaviour and did not normally reflect upon its meanings. This observation was very common among our participants, and this coincide with the Chinese saying “xiguanchengziran” (習慣成自然), meaning that once a habit is formed, it becomes something very natural and thus difficult to change. Walking thus is a common and natural activity for our participants to do every day.

For instance, Kwan, a young woman who worked full-time and travelled by bus every day, talked about how she felt while walking from home to the bus stop every morning and got used to her "fine" short trips:

"I cannot say I feel excited when I walk, [and] it's not relaxing or stressful ... I come across the same buildings, and I walk along the same path every day. It's already a regular routine of mine...To be honest, when you see the same things every day, you will not pay attention to any particular things. Maybe I'll pay attention to something in the very beginning, but with time passed by and you keep walking along the same route, you will not pay special attention to any of them anymore." [female, 28, Xinzhou, inner-high]

From narratives such as Kwan's, we can infer that walking as habit emerges from the relations between the individuals and their environment as a process in which with repetition, sensation recedes into the background and the activity escapes reflective thought altogether (Schwanen, Banister, \& Anable, 2012). Here, 
urban pedestrians are actively incorporating their physical surroundings, other objects and people to enable this open-ended and self-perpetuating process (Dewey, 1922). Walking becomes something people just do during which they can turn their minds to other matters. Compared to walk-along interviews, in which participants emphasised more on the observable or tangible features of the environment, sedentary interviews allow participants to articulate and reflect on their usual routines and habit associated with their daily walking. In this case, sedentary interviews are more appropriate in discovering such banal practice of walking (Hitchings, 2012).

\subsubsection{Walking to connect}

Several participants saw some of their walking trips as valuable moments while they can spend quality time to develop connections, intimacy and sense of trust with their significant others. The idea of considering walking as a meaningful social activity coincides with the work by Laurier et al. (2008), who explored the interactions of friends, families, and colleagues traveling in private vehicles and demonstrated that a car can act as a social space and that traveling together is in fact a valuable social activity in and of itself. For our participants, walking trips play an essential connecting role in their daily lives that they valued so much by centering the trips on communication and affective exchanges.

An example is Lin, a shop owner who had to look after her business the whole day. She valued her short trips for picking up her child from kindergarten. She interpreted her short but important trips as an everyday practice which helped her know more about her son and strengthened their bonding:

"Because of the nature of my work, I don't have much time to walk for leisure... Every morning when I walk my kid to school, I feel it's a brand new day. When I pick him up after school, he tells me what happened in school and what he has learnt. I listen and talk to him... I think he must have learnt something new today, so I feel very good... In my opinion, family is the most important thing. We should always keep family relations in harmony... Although I am the only one responsible for walking my kid to 
school, I appreciate this. This is the moment that belongs to the two of us." [female, 35, Shangjing, outer-high]

For others participants walking trips served to connect them to both their current place of settlement and their ancestral village. For instance, 'walking together' with laoxiang 2 had very special meaning in the lives of participants who had migrated from other parts of China to Shenzhen. They considered walking as not only a common leisure activity but also something they needed to do to help them maintain solid connections with their ancestral origin. These trans-local ties between migrants and their home communities are particularly important, as previous studies have shown that these social ties are associated with better mental health and subjective well-being (Jin, Wen, Fan, \& Wang, 2012; Li \& Chan, 2018; Liu, Zhang, Liu, Li, \& Wu, 2019).

This practice, then, becomes an important means to connect people to different places, which manifests the broader Chinese cultural customs of appreciating kinship, ancestral roots and even collectivism. For example, Mao, among others, said that she enjoyed walking to the plaza nearby to meet with laoxiang, and then they walked together and shared the news in their ancestral home:

"I have a lot of laoxiang living in this neighborhood. Futian Sports Park and Cultural Plaza are my favorite places to meet with my friends. When I go shopping, we usually meet there and go together. It is like, we still keep connected with our hometown. We still have updated information about our ancestral village and other fellows who remain living there." [female, 40, Xinzhou, inner-high]

Another, slightly different, example of connection comes from Tam. She moved from her hometown to Shenzhen and started to live in her present neighborhood 20 years ago. Her walking was so meaningful that it completely changed her early time in Shenzhen. She illustrates how her walking to the park helped her

\footnotetext{
${ }^{2}$ Laoxiang (老 $\square$ ) is a common term in Chinese, indicating ancestral fellows who are originated from the same geographical area of China.
} 
build connections to, and belongingness in, the new place of settlement:

"I knew no one from this neighborhood at the beginning. I started to walk to Huanggang Park for relaxation and exercise. It took me 20 minutes [from home to the park]. There were a lot of activity groups in the park, dancing, singing, Taichi, etc. You could choose what you like and participate... I 'discovered' my activity group and joined one of the dancing groups. Gradually I made friends with some of my dancing group members. Now I look forward to going to the park every day to meet my friends and dance together... We also arrange other group activities like singing karaoke, group tours overseas or go short trip within Guangdong province." [female, 58, Xinzhou, inner-high]

\subsubsection{Walking as regimen}

Walking was also attached to a specific meaning of regimen (yangsheng 養生) and perceived as an important way to stay healthy by many participants. In Chinese, yangsheng is an integrated concept that relates to not only improving physical fitness, but also maintaining internal and external harmony, through exercise, diet, and even spiritual practice (Zhou, Zhang, \& Du, 2017). Many participants interpreted walking as a major part of a nurturing life, and their interpretation of walking differed from the emphasis of bodily fitness that has been established in studies in the western world (Pooley et al., 2013). The participants' interpretation is deeply embedded in the Chinese traditional thinking of "prevention is much more important than treatment", which can be traced back to one of the basic principles in Chinese medicine (Yang et al., 2018; Chen, Song, Hu, \& Brunner, 2012). Many participants referred to the old Chinese saying "with one hundred steps after dinner, you will live to 99 years old" when they talked about their walking habits. This suggests that walking plays a vital role in Chinese people's growing awareness of maintaining health. To these urban walkers, walking is not just a practice to relieve stress and recover from fatigue, but more as a preventative activity to stick to for potentially limiting illness. This preventative function of walking was particularly highlighted by those individuals who expressed more concerns over healthiness and regimen, 
although several have also mentioned the therapeutic effects of walking. They expressed that aesthetically pleasing views, fresh air, and well-regulated traffic and walking environment all made them feel "much better", "relaxed" and "energised".

For instance, Zhang, a fifty-year old woman who took yangsheng as her major task in her life explained why she saw daily walking contributing to her healthy life:

\footnotetext{
"I walked to a nearby park every day to dance and do exercises. For young people, you may assume Yangsheng is not as important as other things in your life. But to us, we are getting older, walking and doing exercises turn to be a very important task for our lives. It is a long-term thing that you have to insist on so that you can stay away from illness...otherwise it would be too late... [female, 50, Xinzhou, inner-high.]
}

In summary, the narratives from our participants denote that walking is more than just a form of movement, but a way to connect to the new place, maintain social relationships, and preserve emotional connections with ancestral origins. Meanings across multiple geographies are thus associated with the daily practice of walking.

\subsection{Engagements with timescapes}

\subsubsection{Temporal complexity of urban walking experience}

Participants' responses to their urban environments and experiences of their walking trips were shaped by elements of the timescape (Adam, 2008), such as the timing, tempo, rhythm, duration of their walking trips, the sequence of their walking routes. The temporalities of both the built and social environment were particularly emphasised by many participants, for walking in different time determined their encounters in and responses to the walking environment. Some perceived favorable features of the neighbourhood environment negatively when they were walking in a different time of the day. A clear example of this were 
broad, evenly surfaced pavements that were appreciated in the early morning but experienced as annoying and disrupting the flow of their walking later during the day when hawkers and vendors had arrived (as shown in Figure 2). Wang's explanations are particularly helpful in elaborating this point:

"I like to walk from home to the park on Sunday mornings. It's not noisy and not much traffic then. Hawkers have not arrived yet and it is clean... I feel comfortable to walk in the mornings... but when you walk in the evening, it will be completely different situation. Hawkers occupy the whole footpath, and some restaurants sell their barbecue food on the street. The street is filled with smoke, litter, and water. It will be stressful and chaotic experience when you walk at night." [male, 40, Shangjing, outer-high]

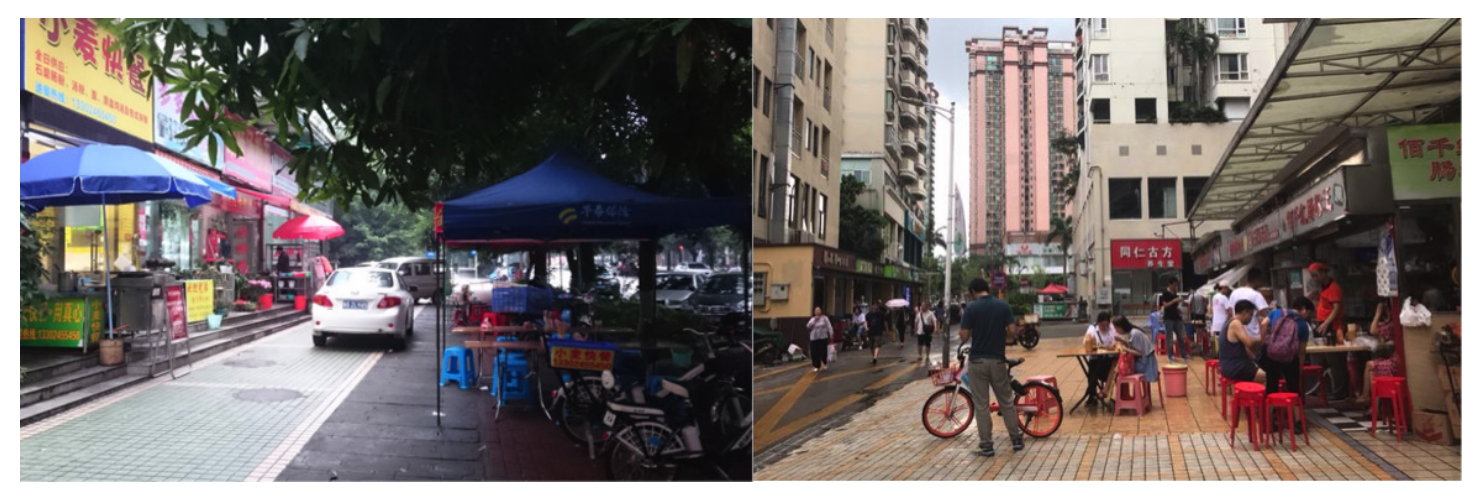

Figure 2. The presence of hawkers and vendors on pedestrian footpaths in late afternoon

Another participant, Liang drew attention to other diurnal rhythms in walking experience. She appreciated urban greenery in her neighbourhood, and enjoyed the shade of trees on her footpaths particularly during Shenzhen's hightemperature summers. Nonetheless, she also concerned that these trees blocked the streetlights when she walked at night, making the same street unsafe after dark:

"I like to walk along Long Cheng Road during daytime, [because] there are trees on both sides of the road, and they are so green and lush. I can relax my eyes by looking at them, and I will not get sun burnt if I forget to bring 
my umbrella with me... but the branches and leaves of the trees block the street lights at night, this makes the footpath very dark... there are no shops or buildings along this road, and sometimes I feel scared while walking at night alone." [female, 25, Huilongpu, outer-low]

\subsubsection{The significance of "futurescapes"}

The temporal elements in understanding urban walking experience were also manifested in our participants' discussions of their socio-environmental future. The way in which they situated their present and past experiences into a larger timeframe associated with their hopes, plans, fears, and expectations was also articulated as significant in producing their walking experiences. This theme is particularly important in light of Shenzhen's ongoing urban transformation, whereby construction work either short-term (e.g. a few months) or long-term (5-10 years) such as construction of different lines of mass transit, the redevelopment of urban villages ${ }^{3}$ (Chengzhongcun) can be observed in many inner and outer urban areas. This urban (re)development has caused aspects of the built environment in Chinese cities to change significantly, in particular its uses and the practices occurring in it (Law, 2005), and encountering construction sites was a common experience for most of our participants. They nonetheless expressed optimistic views about the transformations that their neighbourhoods were undergoing and imagined how the narrow and absent sidewalk would be different in the near future. Kwan, for example, mentioned a short-term construction project undergoing in her neighbourhood caused disruptions against pedestrians (as shown in Figure 3). But interestingly, she talked more about her expectations for the future and she felt optimistic when she was walking past the construction site:

"They are building a new metro station opposite to the shopping mall. Roads and sidewalks are blocked; we don't have enough space to walk, [for] construction wastes are everywhere. But I am more used to this now. I

\footnotetext{
${ }^{3}$ Urban villages in Chinese cities were originally rural settlements that became absorbed into urban areas as transitional neighbourhoods under unregulated rapid urbanisation. They are usually characterised by apartment blocks of $2-8$ floors in close proximity of each other.
} 
understand it is a necessary process when a city is developing. All these negative impacts are unavoidable... But I am sure the situation will be changed once all the work is done...so I feel ok walking along this route...I am always thinking It will be more convenient to travel in the future because we will have a metro station here!" [female, 28, Xinzhou, innerhigh]

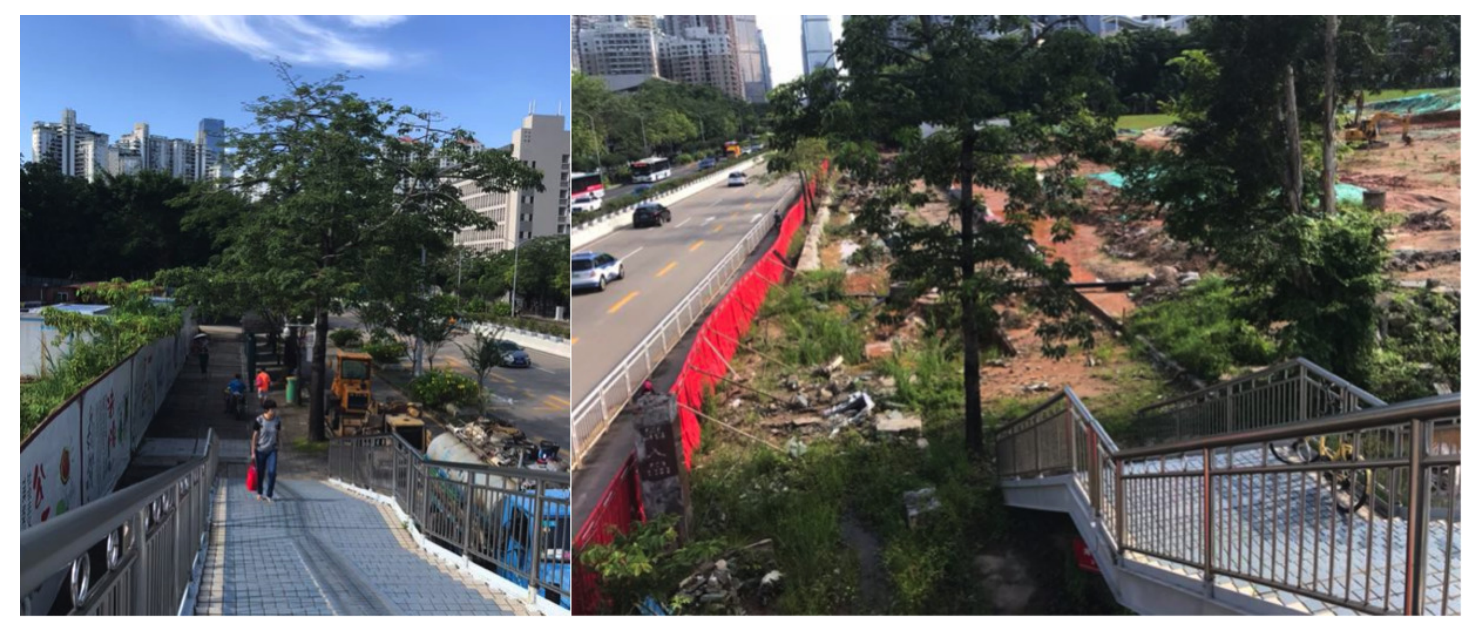

Figure 3 Construction sites narrowing pedestrian footpaths and creating walking obstacles

Participants also related their current walking experience to their future bodily capacities. For example, Guo, who described that the hawkers were common in his neighbourhood, explained he had to walk very carefully when he was exhausted after work. He also talked about the future, expressing more concerns over walking in his neighbourhood:

"I think I am quite fit right now compared to my friends and family. I am pretty flexible to avoid the vendors and hawkers. But I will become older and I may not be as fit or flexible as I am now. I am older, may need to use a cane in the future, I don't think I can walk along this road any more. It is far too difficult to pass these obstacles for the elderly, those who need wheelchair, or visually impaired... it will be impossible for them to pass... [male, 53, Xinsha, inner-low] 
Narratives such as this suggest that understanding urban walking experience does not only connect present to the past, but also to how people expect the future to be. What we do and feel in our lives is not just embedded in our sociohistorical past, but also projected into a socio-environmental future (Adam, 2008; Li \& Chan, 2020). As such, how pedestrians perceive urban walking is relational, implicating their past and future which expand and contract when they move along their life course (Adam, 2008). This observation aligns with the literature on ageing that explained how older pedestrians' level of mobility changes in their later life (Ziegler \& Schwanen, 2011). Nonetheless, the participant's narratives show a more complicated relationship connecting the present and future, emphasising that futurescapes may override the short-term negative impacts of the changing built environment on residents' walking experience.

The participants' elaborations draw attention to the temporal complexities of urban pedestrians' walking experience and the relationships between people's body, their walking behaviour, and environments. Most current environmental studies on walking tend to capture the built environment at a given time period of day, usually in daytime, which may be overlooking the dynamics across multiple timescales in the associations between the built environment and people's walking behaviour. Embracing the complexity of time will help researchers to challenge implicit assumptions in current frameworks of more or less stable associations between context and walking and question whether walking and environmental studies should be constrained to attending to the availability/presence of the built environment features (Lu et al., 2018; Ghani, Rachele, Loh, Washington, \& Turrell, 2018).

\subsection{Engagements with places}

How individuals engage with places was also identified as significant in shaping urban pedestrian's behaviour and walking experiences. These engagements include their physical and emotional bonding with their neighbourhood (shequ), district (qu), or city (Shenzhen), the level of their place dependence, and how they identified with these places. Some talked about how their relationships with 
these places affect their walking experience in the neighbourhood. For instance, when Tam talked about the chaotic walking environment in her neighbourhood because of the metro construction, she emphasised she had been living in this neighbourhood for over ten years, and felt the place was her home. This expression concurs with the literature on place attachment, stating the positive associations between people's attachment to place and length of residency (Brown, Perkins, \& Brown, 2003; Lewicka, 2011). However, she further elaborates that because of her strong attachment to the neighbourhood, she was more tolerant of the chaotic walking environment, and would still keep walking despite the construction works. She said:

“The construction works are annoying, but it is my neighborhood, isn't it? It will get better after these works [are done] ... We will have better living conditions, the property prices in this district will be much higher... We will have a metro station right here that can take us to anywhere in Shenzhen... this is my neighborhood, so I want to see it improved." [female, 58, Xinzhou, inner-high]

Shao's articulations about how her life was dependent on the park and plaza nearby, where she usually brought her child for leisure walking, suggested strong place attachment as well. She shared:

"My life will be different if we were not living nearby Futian Sports Park and the Plaza. It's very lively there even at night: children play in the plaza and ladies can dance. There are also lights everywhere, and a big TV screen that we can watch news...they put fences around so that we don't need to worry about children going outside... it had a construction work on the way to the park, it was chaotic. But I felt fine. Before the construction work, the road surface was not even, and it was difficult for me to push my baby stroller. They spent some time resurfacing it, and now it is much easier for me to walk [to my park]." [female, 44, Xinzhou, inner-high]

Our participants' narratives revealed how their attachment to neighbourhood 
plays an important role in mediating their walking experiences (Gustafson, 2001). However, previous studies have only demonstrated positive environmental perception was a strong contributing factor to place attachment, while the role of place attachment on environmental perception was unclear (Mesch \& Manor, 1998; Bonaiuto, Aiello, Perugini, Bonnes, \& Ercolani, 1999). Our participants' narratives have suggested that a strong sense of place attachment may led to a more optimistic view in perceiving the walking environment, despite the chaotic conditions that they had to endure during the construction. This demonstrated a possible bi-directional relationship between participants' place attachment and perceptions of the neighbourhood environment that has not been examined in existing literature.

\section{Conclusion}

The qualitative analysis of Shenzhen pedestrians' narratives led to the identification of three major themes for understanding urban walking experiences in the Chinese context. These three themes demonstrated that urban pedestrians' experiences are entangled with the meanings ascribed to walking and with their engagements with timescapes and with places; these themes will combine to or individually shape people's walking experience in important yet subtle ways. In combination, these themes bring forward a more contextualised comprehension of how urban pedestrians interpret, respond to, and perceive their environments. The following insights can be derived from the analysis discussed above.

First, walking is a culturally specific behaviour, and cultural differences, social norms, and values will all play a role in shaping pedestrians' experience. Despite there being several important parallels between participants' articulations in this study and in earlier work (e.g. Pooley et al., 2014; Middleton, 2018), several differences in terms of meanings, perceived benefits, and the discourses around walking with previous research can be identified. For example, our study participants did not have much to say about the cost aspects of walking, or about connotations of walking with low socio-economic status, psycho-social stress, etc. (Segar et al., 2017). With regard to health benefits, the participants in the 
current study did not talk as much about the therapeutic and restorative functions of urban walking (Doughty, 2013; Gatrell, 2013) and placed only limited emphasis on the bodily fitness resulting from walking as exercise. Instead, the discourse tended to centre on harmony and balance: walking was seen as a way to maintain harmony between their mind, body, and the environment. This focus reflects a broader concern with harmony in health promotion and a focus on prevention - walking as regimen - over treatment that is deeply embedded in Chinese culture (Kwok \& Sullivan, 2007).

Second, the participants in the present study talked extensively about obstructions to urban walking due to construction works and unregulated commercial activities along streets, implying the rapid urban transformation that Shenzhen is undergoing while also exhibiting characteristics that are often associated with streets in other cities in the global South. Discourses about these obstructions were, however, optimistic as it seemed to be widely expected that those obstructions were temporary and would diminish in the future. Such observations have not been reported in earlier walking studies. Our participants have explained that such positive attitudes can be attributed to the continuous improvements they have experienced in the past years. They have witnessed how their neighbourhood has become a better place to live. Such thinking leads to a more positive attitude in accepting the short-term inconvenience brought to their neighbourhoods.

Third, our findings also highlight the significance of temporality in understanding how the built environment affects walking experience. In previous studies, the built environment and its presumed effects on walking have mostly been treated as static or at best as only slowly changing. Hence, policydirected and targeted changes in urban design are considered an important means to modify the built environment in existing walkability studies. However, our findings highlight that people's walking experiences are shaped in complex ways by all kinds of short-term dynamics in the built and social environment, which concern how physical space is used and the practices it affords at specific moments. Consider, for instance, the presence of commercial activities on 
sidewalks. Not only can their physical appearance change over the course of the day, week or month; these activities can also afford different experiences for pedestrians at different moments in time. They can act, and be regarded, as obstacles during morning peak hours when pedestrians are rushing to get to work on time, but they can also be experienced as a source of personal safety (presence of other people on street) when they walk at night. As Andrews et al. (2012) posit, much of the urban planning and design literature on walkability tends to use standardised scales in design manuals and technical guidelines to assess walkability, like walking speeds and distances. Such practices overlook the differences in pedestrians' bodily capacities, the time of day that the walking take place, and the emotional experiences of walking. As a result, it is proposed here that walkability should be understood more comprehensively than just as urban design. The ways in which pedestrians experience the walking environment, the temporal variability of the environment, as well as the differences in pedestrians' bodily capacity should also be considered.

As one of the first studies to explore walking experience in the Chinese context, it suggests that understandings about walking experience and also of walkability developed from studies in western cities should not be transposed directly to cities in China, and possibly elsewhere outside the West. If those understandings are directly transposed, important dimensions of urban walking and walkability that are embedded in local cultures and histories are likely to be disregarded. Explorative studies in non-western cities, such as the current one, can bring more context-sensitivity to attempts to promote walking. The findings of studies such as this also enable future studies to reconceptualise and measure walkability not only as a static entity but a dynamic process that involves relations and interactions of pedestrians with the walking environment. Insights from this study might also prove useful to policy-makers in acknowledging the diversified meanings that walking has for various pedestrians, and hence to consider appropriate policies in designing walkable cities. 


\section{Acknowledgement:}

The authors are very grateful for the participants who were interested in this study and kindly shared their walking experiences. We also like to express our sincere gratitude to the three anonymous reviewers for their comments and suggestions that have significantly improved the quality of this paper. 


\section{References:}

Adam B. (2008). Of timescapes, futurescapes and timeprints. Lüneburg University.

Aldred, R., \& Jungnickel, K. (2014). Why culture matters for transport policy: the case of cycling in the UK. Journal of Transport Geography, 34, 78-87.

Almahmood, M., Scharnhorst, E., Carstensen, T. A., Jørgensen, G., \& Schulze, 0. (2017). Mapping the gendered city: investigating the socio-cultural influence on the practice of walking and the meaning of walkscapes among young Saudi adults in Riyadh. Journal of Urban design, 22(2), 229248.

Ambrey, C., \& Bitzios, M. (2018). Demystifying residents' walking behaviors: active transport in South East Queensland, Australia. International journal of sustainable transportation, 12(10), 737-752.

Andrews, G. J., Hall, E., Evans, B., \& Colls, R. (2012). Moving beyond walkability: On the potential of health geography. Social Science \& Medicine, 75(11), 1925-1932.

Atkinson, S. (2013). Beyond components of wellbeing: The effects of relational and situated assemblage. Topoi, 32(2), 137-144.

Bean, C. E., Kearns, R., \& Collins, D. (2008). Exploring social mobilities: Narratives of walking and driving in Auckland, New Zealand. Urban Studies, 45(13), 2829-2848.

Bonaiuto, M., Aiello, A., Perugini, M., Bonnes, M., \& Ercolani, A. P. (1999). Multidimensional perception of residential environment quality and neighbourhood attachment in the urban environment. Journal of environmental psychology, 19(4), 331-352.

Boyatzis, R. E. (1998). Transforming qualitative information: Thematic analysis and code development. California, USA: Sage Publications.

Brown, B., Perkins, D. D., \& Brown, G. (2003). Place attachment in a revitalizing neighborhood: Individual and block levels of analysis. Journal of environmental psychology, 23(3), 259-271.

Bruner, J. S. (1990). Acts of meaning. Cambridge, MA: Harvard University Press.

Büscher, M., \& Urry, J. (2009). Mobile methods and the empirical. European Journal of Social Theory, 12(1), 99-116. 
Carpiano, R. M. (2009). Come take a walk with me: The "Go-Along" interview as a novel method for studying the implications of place for health and wellbeing. Health \& place, 15(1), 263-272.

Chan, E. T. H., Schwanen, T., \& Banister, D. (2019). The role of perceived environment, neighbourhood characteristics, and attitudes in walking behaviour: evidence from a rapidly developing city in China. Transportation, 1-24.

Chen, R., Song, Y., Hu, Z., \& Brunner, E. J. (2012). Predictors of diabetes in older people in urban China. PloS one, 7(11), e50957.

Coulton, C. J., Jennings, M. Z., \& Chan, T. (2013). How big is my neighborhood? Individual and contextual effects on perceptions of neighborhood scale. American journal of community psychology, 51(1-2), 140-150.

Curl, A., Kearns, A., Macdonald, L., Mason, P., \& Ellaway, A. (2018). Can walking habits be encouraged through area-based regeneration and relocation? A longitudinal study of deprived communities in Glasgow, UK. Journal of Transport \& Health, 10, 44-55.

Curl, A., Ward Thompson, C., Aspinall, P., \& Ormerod, M. (2016). Developing an audit checklist to assess outdoor falls risk. Proceedings of the Institution of Civil Engineers-Urban Design and Planning, 169(3), 138-153.

de Melo, L. L., Menec, V., Porter, M. M., \& Ready, A. E. (2010). Personal factors, perceived environment, and objectively measured walking in old age. Journal of aging and physical activity, 18(3), 280-292.

Deleuze, G., \& Guattari, F. (1988). A thousand plateaus: Capitalism and schizophrenia. Minneapolis: University of Minnesota Press.

Dewey, J. (1922). Human nature and conduct; an introduction to social psychology. New York: H. Holt \& Company.

Doughty, K. (2013). Walking together: the embodied and mobile production of a therapeutic landscape. Health \& Place, 24, 140-146.

Dovey, K., \& Pafka, E. (2019). What is walkability? The urban DMA. Urban Studies, 0042098018819727.

Edensor, T. (2010). Walking in rhythms: Place, regulation, style and the flow of experience. Visual Studies, 25(1), 69-79.

Elmir, R., Schmied, V., Jackson, D., \& Wilkes, L. (2011). Interviewing people about 
potentially sensitive topics. Nurse researcher, 19(1).

Ferreira, I. A., Johansson, M., Sternudd, C., \& Fornara, F. (2016). Transport walking in urban neighbourhoods-Impact of perceived neighbourhood qualities and emotional relationship. Landscape and urban planning, 150, 60-69.

Fitt, H. (2017). Do social meanings matter? How and how much social meanings influence everyday transport practices?. New Zealand Geographer, 73(3), 181-191.

Gatrell, A. C. (2013). Therapeutic mobilities: walking and 'steps' to wellbeing and health. Health \& Place, 22, 98-106.

Ghani, F., Rachele, J. N., Loh, V. H., Washington, S., \& Turrell, G. (2018). Do differences in built environments explain age differences in transport walking across neighbourhoods?. Journal of Transport \& Health, 9, 83-95.

Guest, G., Bunce, A., \& Johnson, L. (2006). How many interviews are enough? An experiment with data saturation and variability. Field Methods, 18(1), 5982.

Gustafson, P. (2001). Meanings of place: Everyday experience and theoretical conceptualizations. Journal of environmental psychology, 21(1), 5-16.

Hennink, M. M., Kaiser, B. N., \& Marconi, V. C. (2017). Code saturation versus meaning saturation: how many interviews are enough?. Qualitative health research, 27(4), 591-608.

Hitchings, R. (2012). People can talk about their practices. Area, 44(1), 61-67.

Horton, J., Christensen, P., Kraftl, P., \& Hadfield-Hill, S. (2014). 'Walking... just walking': how children and young people's everyday pedestrian practices matter. Social \& Cultural Geography, 15(1), 94-115.

Ingold, T., \& Vergunst, J. L. (2008). Ways of walking: Ethnography and practice on foot. Hampshire, UK: Ashgate Publishing, Ltd.

Jin, L., Wen, M., Fan, J. X., \& Wang, G. (2012). Trans-local ties, local ties and psychological well-being among rural-to-urban migrants in Shanghai. Social science \& medicine, 75(2), 288-296.

Johansson, M., Sternudd, C., \& Kärrholm, M. (2016). Perceived urban design qualities and affective experiences of walking. Journal of Urban design, 21(2), 256-275.

Kelly, P., Murphy, M., \& Mutrie, N. (2017). The health benefits of walking. In C. 
Mulley, K. Gebel \& D. Ding (Eds.), Walking (Transport and Sustainability) (Vol. Volume 9, pp. 61-79): Emerald Publishing Limited.

Kerr, C., Nixon, A., \& Wild, D. (2010). Assessing and demonstrating data saturation in qualitative inquiry supporting patient-reported outcomes research. Expert review of pharmacoeconomics \& outcomes research, 10(3), $269-281$.

Kwan, M. P. (2018). The limits of the neighborhood effect: Contextual uncertainties in geographic, environmental health, and social science research. Annals of the American Association of Geographers, 108(6), 1482-1490.

Kwan, M. P., \& Schwanen, T. (2018). Context and uncertainty in Geography and GIScience: Advances in theory, method, and practice. Annals of the American Association of Geographers, 108(6), 1473-1475.

Kwok, C., \& Sullivan, G. (2007). The concepts of health and preventive health practices of Chinese Australian women in relation to cancer screening. Journal of Transcultural Nursing, 18(2), 118-126.

Laurier, E., Lorimer, H., Brown, B., Jones, O., Juhlin, O., Noble, A., . . . Strebel, I. (2008). Driving and 'passengering': Notes on the ordinary organization of car travel. Mobilities, 3(1), 1-23.

Law, L. (2005). Sensing the city: urban experiences. In P. Cloke, P. Crang \& M. Goodwin (Eds.), Introducing human geographies (pp. 439-450). London: Arnold.

Lee, B. A., Oropesa, R. S., \& Kanan, J. W. (1994). Neighborhood context and residential mobility. Demography, 31(2), 249-270.

Lefebvre, H. (2004). Rhythmanalysis: Space, time and everyday life. A\&C Black.

Lewicka, M. (2011). Place attachment: How far have we come in the last 40 years? Journal of environmental psychology, 31(3), 207-230.

Li, T. E., \& Chan, E. T. H. (2018). Connotations of ancestral home: An exploration of place attachment by multiple generations of Chinese diaspora. Population, Space and Place, 24(8), e2147.

Li, T. E., \& Chan, E. T. H. (2020). Diaspora tourism and well-being over lifecourses. Annals of Tourism Research, 82, 102917.

Liu, Y., Zhang, F., Liu, Y., Li, Z., \& Wu, F. (2019). Economic disadvantages and 
migrants' subjective well-being in China: The mediating effects of relative deprivation and neighbourhood deprivation.Population, Space and Place, 25(2), e2173.

Lorimer, H. (2011). Walking: new forms and spaces for studies of pedestrianism. In T. Cresswell \& P. Merriman (Eds.), Geographies of mobilities: Practices, spaces, subjects (pp. 19-33): Ashgate Publishing Limited.

Lorimer, H., \& Lund, K. (2008). A collectable topography: walking, remembering and recording mountains. In T. Ingold \& J. L. Vergunst (Eds.), Ways of walking: Ethnography and practice on foot (pp. 318-345). Aldershot, UK: Ashgate.

Lu, Y., Sarkar, C., \& Xiao, Y. (2018). The effect of street-level greenery on walking behavior: Evidence from Hong Kong. Social Science \& Medicine, 208, 4149.

Mennis, J., \& Mason, M. J. (2011). People, places, and adolescent substance use: Integrating activity space and social network data for analyzing health behavior. Annals of the Association of American Geographers, 101(2), 272291.

Mesch, G. S., \& Manor, O. (1998). Social ties, environmental perception, and local attachment. Environment and Behavior, 30(4), 504-519.

Middleton, J. (2009). 'Stepping in time': walking, time, and space in the city. Environment and Planning A, 41(8), 1943-1961.

Middleton, J. (2010). Sense and the city: exploring the embodied geographies of urban walking. Social \& Cultural Geography, 11(6), 575-596.

Middleton, J. (2011). "I'm on Autopilot, I Just Follow the Route": Exploring the Habits, Routines, and Decision-Making Practices of Everyday Urban Mobilities. Environment and Planning A, 43(12), 2857-2877.

Middleton, J. (2018). The socialities of everyday urban walking and the 'right to the city'. Urban Studies, 55(2), 296-315.

Orton, L., Halliday, E., Collins, M., Egan, M., Lewis, S., Ponsford, R., ... \& Popay, J. (2017). Putting context centre stage: evidence from a systems evaluation of an area based empowerment initiative in England. Critical Public Health, 27(4), 477-489.

Pinder, D. (2005). Arts of urban exploration. Cultural Geographies, 12(4), 383- 
411.

Pooley, C. G., Horton, D., Scheldeman, G., Mullen, C., Jones, T., \& Tight, M. (2014). 'You feel unusual walking': The invisible presence of walking in four English cities. Journal of Transport \& Health, 1(4), 260-266.

Pooley, C., Jones, T., Tight, M., Horton, D., Scheldeman, G., Mullen, C., . . . Strano, E. (2013). Promoting walking and cycling: New perspectives on sustainable travel Bristol, UK: Policy Press.

Ritchie, J., Lewis, J., Nicholls, C. M., \& Ormston, R. (Eds.). (2013). Qualitative research practice: A guide for social science students and researchers. sage.

Schwanen, T. (2018). Geographies of transport III: New spatialities of knowledge production? Progress in Human Geography, 42(3), 463-472.

Schwanen, T., Banister, D., \& Anable, J. (2012). Rethinking habits and their role in behaviour change: the case of low-carbon mobility. Journal of Transport Geography, 24, 522-532.

Segar, M. L., Heinrich, K. M., Zieff, S. G., Lyn, R., Gustat, J., Perry, C. K., ... \& Eyler, A. A. (2017). What walking means to moms: Insights from a national sample to frame walking in compelling ways to low-income urban mothers. Journal of Transport \& Health, 5, 5-15.

Shortell, T., \& Brown, E. (2014). Walking in the European city: Quotidian mobility and urban ethnography. Farnham: Ashgate Publishing.

Silverman, D. (2015). Interpreting qualitative data. London, UK: Sage Publications Ltd.

Stephenson, J., Barton, B., Carrington, G., Doering, A., Ford, R., Hopkins, D., . . Scott, M. (2015). The energy cultures framework: Exploring the role of norms, practices and material culture in shaping energy behaviour in New Zealand. Energy Research \& Social Science, 7, 117-123.

Strauss, A., \& Corbin, J. (1998). Basics of qualitative research: Techniques and procedures for developing grounded theory. Thousand Oaks: Sage Publications.

Taylor, L. G., Clark, A. F., \& Gilliland, J. A. (2018). Context Matters: Examining children's perceived barriers to physical activity across varying Canadian environments. Health \& place, 54, 221-228.

Vale, D. S., Saraiva, M., \& Pereira, M. (2016). Active accessibility: A review of 
operational measures of walking and cycling accessibility. Journal of Transport and Land Use, 9(1), 209-235.

Viner, R. M., Ozer, E. M., Denny, S., Marmot, M., Resnick, M., Fatusi, A., \& Currie, C. (2012). Adolescence and the social determinants of health. The Lancet, 379(9826), 1641-1652.

Waitt, G., Stratford, E., \& Harada, T. (2019). Rethinking the geographies of walkability in small city centers. Annals of the American Association of Geographers, 109(3), 926-942.

Wunderlich, F. M. (2008). Walking and rhythmicity: Sensing urban space. Journal of Urban Design, 13(1), 125-139.

Wylie, J. (2009). Landscape, absence and the geographies of love. Transactions of the Institute of British Geographers, 34(3), 275-289.

Yang, J., Siri, J. G., Remais, J. V., Cheng, Q., Zhang, H., Chan, K. K. Y., . . Li, X. (2018). The Tsinghua-Lancet Commission on Healthy Cities in China: unlocking the power of cities for a healthy China. The Lancet, 391(10135), 21402184.

Ziegler, F., \& Schwanen, T. (2011). 'I like to go out to be energised by different people': an exploratory analysis of mobility and wellbeing in later life. Ageing \& Society, 31(5), 758-781.

Zhou, X. q., Zhang, D. q., \& Du, J. k. (2017). Difference and Integration: An analysis of P.E. Health Preserving Culture Between China and the West. Journal of Beijing Sport University, 40(4), 133-138. 